\title{
ARTICLE \\ Isolation of prostrate turfgrass mutants via screening of dwarf phenotype and characterization of a perennial ryegrass prostrate mutant
}

Junmei Chen ${ }^{1,2,5}$, Chandra Thammina ${ }^{2,5}$, Wei $\mathrm{Li}^{2}$, Hao $\mathrm{Yu}^{2}$, Huseyin Yer ${ }^{2}$, Rania El-Tanbouly ${ }^{2}$, Manon Marron ${ }^{2}$, Lorenzo Katin-Grazzini ${ }^{2}$, Yongqin Chen ${ }^{2,3}$, John Inguagiato ${ }^{2}$, Richard J. McAvoy ${ }^{2}$, Karl Guillard ${ }^{2}$, Xian Zhang ${ }^{4}$ and Yi Li ${ }^{2}$

Prostrate turf varieties are desirable because of their increased low mowing tolerance, heat resistance, traffic resistance and ground coverage compared with upright varieties. Mutation breeding may provide a powerful tool to create prostrate varieties, but there are no simple, straightforward methods to screen for such mutants. Elucidation of the molecular basis of the major 'green revolution' traits, dwarfism and semi-dwarfism, guided us to design a simple strategy for isolating dwarf mutants of perennial ryegrass (Lolium perenne L.). We have shown that gamma-ray-mediated dominant dwarf mutants can be easily screened for at the three-leaf stage. About $10 \%$ of dwarf mutant lines also displayed a prostrate phenotype at mature stages ( $>10$ tillers). One prostrate line, Lowboy I, has been characterized in detail. Lowboy I had significantly shorter canopy, leaf blade and internode lengths compared with wild type. Lowboy I also exhibited greater tolerance to low mowing stress than wild type. Exogenous gibberellic acid (GA) restored Lowboy I to a wild-type phenotype, indicating that the dwarf and prostrate phenotypes were both due to GA deficiency. We further showed that phenotypes of Lowboy I were dominant and stably inherited through sexual reproduction. Prostrate turfgrass mutants are difficult to screen for because the phenotype is not observed at young seedling stages, therefore our method represents a simple strategy for easily isolating prostrate mutants. Furthermore, Lowboy I may provide an outstanding germplasm for breeding novel prostrate perennial ryegrass cultivars.

Horticulture Research (2016) 3, 16003; doi:10.1038/hortres.2016.3; Published online 24 February 2016

\section{INTRODUCTION}

Perennial ryegrass (Lolium perenne L.) is an important turfgrass species, widely used for lawns and athletic fields because of its rapid establishment and attractive, leafy appearance. ${ }^{1,2}$ Because of its fast growth rate, perennial ryegrass requires frequent watering, fertilization and mowing, resulting in high establishment and maintenance costs. ${ }^{3,4}$ One strategy to reduce upkeep costs would be to use a dwarf variety of perennial ryegrass, ${ }^{5-7}$ however, none exists as of yet. Dwarf mutants can have lower upkeep costs due to their reduced vegetative growth, which necessitates less frequent mowing and fewer nutrients, and thus makes them less vulnerable to evaporation.

Another strategy would be to create a prostrate variety of perennial ryegrass. Prostrate turf has been shown to improve low mowing tolerance in bluegrass (Poa spp.). ${ }^{8}$ The horizontal growth of prostrate turf can protect leaf blades and sheaths, aiding in recovery from mowing stress. Young leaf blades, which are more photosynthetically active compared with older leaves, are more likely to be removed by mowing in upright varieties. ${ }^{9}$ Prostrate turf also appears to have higher heat tolerance because the plant crowns are shielded from the heat when they are far below the surface of the mat layer. ${ }^{10}$ Prostrate turf varieties have the potential to be more traffic resistant than upright varieties, whose leaves and stems are more likely to be damaged when subjected to traffic. Turf that grows in a prostrate manner appears to have greater ground coverage than upright turf because the flat-lying leaves can cover areas with lower turf density.

Induced mutation combined with selective breeding, a technique known as mutation breeding, is highly efficient for developing plant cultivars with improved traits. According to statistics released by the Food and Agriculture Organization of the United Nations in conjunction with the International Atomic Energy Agency, $>2,600$ novel cultivars of 214 plant species have been developed by mutation breeding. ${ }^{11}$ Gamma-ray irradiation was used to produce most of these mutant crop species. ${ }^{12,13}$ Gamma-ray irradiation has been used to induce changes in the morphology, cold tolerance and growth habits of centipedegrass (Eremochloa ophiuroides) and St Augustinegrass (Stenotaphrum secundatum). ${ }^{14,15}$ A variety of rhodes grass (Chloris gayana Kunth) created by gamma-ray irradiation exhibited a chlorophyll mutation in addition to sterility and other morphological variation. ${ }^{16}$ Dwarf, drought resistant and triploid Bermudagrass (Cynodon dactylon) mutants were also created using gamma-ray irradiation. ${ }^{17-22}$ Using mutation breeding to develop new cultivars of perennial ryegrass is difficult because it is self-incompatible. ${ }^{23}$ In order to screen for new traits, they must be the result of one or more dominant mutations. Recessive mutations will not manifest as visible phenotypes because mutant alleles will never exist in a homozygous state owing to the inability of perennial ryegrass to self-cross.

\footnotetext{
${ }^{1}$ College of Landscape Architecture and Arts, Northwest A\&F University, Yangling 712100, China; ${ }^{2}$ Department of Plant Science and Landscape Architecture, University of Connecticut, Storrs, CT 06269, USA; ${ }^{3}$ College of Life Sciences, Hubei University, Wuhan 430062, China and ${ }^{4}$ College of Horticulture, Northwest A\&F university, Yangling 712100 , China ${ }^{5}$ These two authors contributed equally to this work.

Correspondence: Y Li (yi.li@uconn.edu)

Received: 10 January 2016; Revised: 18 January 2016; Accepted: 18 January 2016
} 
The 'green revolution' is a term applied to the period following the development of numerous dwarf, and semi-dwarf, varieties of important agricultural crop plants. It was later discovered that the semi-dwarf wheat and rice varieties used in the 'green revolution' were the result of dominant, or semi-dominant, mutations connected to the gibberellic acid (GA) signaling pathway. ${ }^{24,25}$ GA deficiency, or insensitivity can result in a dwarf phenotype, carrying along with secondary phenotypes associated with dwarfism. For example, the semi-dwarf wheat (Triticum spp.) and rice (Oryza spp.) varieties used in the 'green revolution' had a secondary phenotype of increased grain yield.

Here we report a simple strategy for isolating a prostrate mutant of perennial ryegrass through screening for dominant dwarf mutations. We also report a detailed characterization of one of the prostrate mutant lines that we recovered.

\section{MATERIALS AND METHODS}

Plant materials

'Fiesta 4' perennial ryegrass seeds were purchased from the Chas. C. Hart Seed Co. located in Wethersfield, CT, USA.

\section{Gamma-ray irradiation}

Fiesta 4 perennial ryegrass seeds were immersed in tap water for $24 \mathrm{~h}$ and then irradiated with various doses of gamma rays $(0,2.5,5.0,7.5,10.0,15.0$, and 20.0 kilorad (kr)) from a Cobalt-60 source in the Radiation Laboratory at the University of Massachusetts, Lowell, USA. Each treatment was performed in three replicates, with 1200 seeds per replicate, to determine the effects of radiation dosage on seed germination.

Irradiated seeds were pretreated at $4^{\circ} \mathrm{C}$ for 2 days and allowed to germinate on moist paper towels at $25^{\circ} \mathrm{C}$ under a 16-h light cycle $\left(35-45 \mu \mathrm{mol} \mathrm{m}{ }^{-2} \mathrm{~s}^{-1}\right)$. The lethal dose of gamma-ray irradiation was determined based on seed germination rates after 21 days. The germination rate of each treatment was reported as an average of the three replicates.

Based on the calculated median lethal dose $\left(L_{50}\right)$, a 9.0-kr dose was chosen for subsequent seed treatment. Ten kilograms of Fiesta 4 seeds were irradiated with $9.0 \mathrm{kr}$ of gamma rays as described above. The irradiated seeds (M1 generation) were air-dried for $12 \mathrm{~h}$ and stored at $4{ }^{\circ} \mathrm{C}$.

\section{Field planting and harvesting}

M1 seeds were hand-broadcasted at a density of $1.5 \mathrm{~kg}$ per $100 \mathrm{~m}^{2}$ and grown to maturity at the University of Connecticut, Plant Science Research and Education Facility in Storrs, CT, USA. Progeny seeds were harvested, air-dried at room temperature and were stored at $4{ }^{\circ} \mathrm{C}$.

\section{Identification of dwarf mutants}

A total of 150000 second-generation mutant seeds (M2) were treated with $289 \mu \mathrm{M} \mathrm{GA}_{3}$ for $10 \mathrm{~h}$ to promote uniform germination. Seeds were then rinsed with tap water and held at $4{ }^{\circ} \mathrm{C}$ for 14 days. Cold-treated seeds were germinated and grown in shallow black germination trays $(56 \times 29 \times 3.3 \mathrm{~cm})$ containing Promix potting soil (Premier Horticulture Inc., PA, USA) in the greenhouse, with 3,000 seeds per tray. Two to three weeks later, when seedlings reached the three-leaf stage, dwarf mutants were easily identified. The seedlings that had their leaf blades at least $30 \%$ shorter than the estimated average were transferred to $7.62 \mathrm{~cm}$ plugs and were allowed to grow further for evaluation. Plants that maintained a dwarf phenotype into maturity, as well as in their vegetatively propagated progeny, were named and used for detailed characterization.

\footnotetext{
Morphological characterization of Lowboy I M2 plants under field conditions

One of the dwarf mutants, Lowboy I, was selected for further characterization. M2 Lowboy I and wild-type Fiesta 4 plants were vegetatively propagated and grown in the greenhouse for 2 months in $7.62 \mathrm{~cm}$ plug trays. Plugs with 8-10 tillers each were planted in the field in September 2011, 2012 and 2013. Plugs were planted in rows and spaced $30 \mathrm{~cm}$ apart, with no additional fertilization or irrigation after establishment. Field test plots used a randomized design with six replicates per mutant line and wild type.
}

At the end of each June, from 2012 to 2014, turf planted in the September of previous year was carefully dug out and soil was washed from the roots. Ten representative tillers were picked from each of the six replicates. To measure leaf blade length, leaf blade width and internode length, the tallest three leaves and internodes from each of the 10 tillers were measured. Mean leaf sizes and internode lengths were calculated for each replicate. Canopy lengths, root lengths and ratios of root/shoot biomass were determined using six replicates. For the root/shoot biomass, plant materials were oven-dried at $70^{\circ} \mathrm{C}$ for 10 days and were then weighed. Data were reported as the mean of all replicates.

\section{Evaluation of tolerance to low mowing height}

In September 2011, Lowboy I M2 and wild-type plants were vegetatively propagated on Woodbridge fine sandy loam soil, in a $28 \times 56 \mathrm{~cm}$ area at a density of 16 tillers per $100 \mathrm{~cm}^{2}$ in the greenhouse. In May 2012, greenhouse-grown 8-month-old Lowboy I M2 and wild-type sod strips $(28 \times 56 \mathrm{~cm})$ were randomly planted on Woodbridge fine sandy loam soil under field conditions. Each test line was planted in triplicate. A distance of $30 \mathrm{~cm}$ was left between sod strips in a row and between rows. Sod strips were watered as needed until fully established. Upon establishment, mowing heights for Lowboy I M2 and wild-type sod strips were gradually lowered from 7.62 to $1.90 \mathrm{~cm}$. From June until August (2012-2015), test plots were mowed twice per week with a John Deere JS60 rotary push mower. Turf density, leaf texture and turf quality were determined in the final week of July 2013 according to the procedures described by Morris. $^{26}$

\section{Morphological evaluation of Lowboy I M3 progeny plants}

Lowboy I M2, Gamma-2 M2 and wild-type plants were vegetatively propagated in the greenhouse for the controlled crossings Lowboy I M2 (\$) $\times$ wild-type (o') and Lowboy I M2 (\$) $\times$ Gamma-2 M2 ( $\left.\sigma^{\prime}\right)$. Gamma-2 is another dwarf mutant isolated during the same initial screening as Lowboy I. Plugs of size $7.62 \mathrm{~cm}$ (8-10 tillers each) were planted in the field during September 2012. A distance of $46 \mathrm{~cm}$ was left between each row and $18 \mathrm{~cm}$ was left between plants within a row. Plastic was used to wrap cages surrounding parental plants in order to prevent undesired cross-pollination, after which plants were manually agitated with one another to facilitate pollination. Seeds were harvested separately from each plant, air-dried at room temperature and stored at $4^{\circ} \mathrm{C}$.

Seeds from each crossing were germinated in Pen packs $(15 \times 11 \times 5 \mathrm{~cm}$; K\&C Plastics, Leominster, MA, USA) containing Promix potting soil. After 60 days, the progeny plants were sorted based on height. M3 progeny were divided into two groups: tall and short. Six individual plants were selected from each of the following groups: wild type, Lowboy I M2, Gamma-2 M2, tall progeny of Lowboy I M2 (Q) $\times$ wild type (o'), short progeny of Lowboy I M2 (\$) $\times$ wild type ( $\left(^{r}\right)$ and progeny of Lowboy I M2 (\$) $\times$ Gamma-2 M2 (ơ). These plants were vegetatively propagated in 7.56$\mathrm{cm}$ plug trays containing Promix potting soil. After 60 days, measurements of shoot length, root length, tiller number and dry root/shoot biomass were taken.

\section{GA treatment}

M2 Lowboy I and wild-type Fiesta 4 plants were vegetatively propagated and grown in the greenhouse for 2 months in $7.62-\mathrm{cm}$ plug trays. Plants were then cut to a height of $5 \mathrm{~cm}$, after which they were sprayed once a week with $10 \mathrm{ml}$ (per plant) of a $5 \mathrm{mg} / \mathrm{l} \mathrm{GA}$ solution. The experiment was done with six replicates for the mutant line and wild-type plants. Measurements and photos were taken after 3 weeks of $\mathrm{GA}_{3}$ treatment.

\section{Statistical analysis}

Analysis of variance was performed on data collected from greenhousegrown and field-grown plants using IBM SPSS 19.0 (IBM Corp., Somers, NY, USA). When sufficient differences $(P<0.05)$ were observed, Fisher's least significant difference test $(P=0.05)$ was performed to detect differences between treatments. ${ }^{27}$ Comparison between the mean turf quality characteristics in low mowing experiments of Lowboy I M2 and wildtype plants used two-tailed Student's $t$-tests. 


\section{RESULTS}

In an initial experiment, a range of gamma-ray doses (0-20 kr) was used to treat Fiesta 4 perennial ryegrass seeds, after which the germination rate was tested. Germination rate data were collected 21 days post germination. There was a strong negative correlation between seed germination rate and gamma-ray dosage (Table 1). Compared with untreated seeds, germination rates of 7.5 - and $10.0-\mathrm{kr}$ irradiated seeds were reduced by $39.96 \%$ and $58.68 \%$, respectively (Table 1). A gamma ray dose resulting in a $50 \%$ reduction in seed germination $\left(\mathrm{LD}_{50}\right)$ is often used for mutagenesis experiments. ${ }^{28,29}$ We estimated that a 9.0-kr dose would reduce germination rates by $\sim 50 \%$, and was therefore chosen for subsequent seed treatment. First-generation mutant (M1) seeds were planted in the field and grown to a flowering stage, after which they were allowed to cross randomly. The resultant progeny seeds (M2) were harvested and germinated.

After germination, M2 seeds were visually screened for a dwarf phenotype ( $>30 \%$ reduction in leaf blade length) at the three-leaf stage of seedling development (Figure 1a). More than 75 dwarf mutant lines were recovered from 150000 M2 seedlings, with 51 lines maintaining their dwarfism both into maturity and after vegetative propagation. At the vegetative maturity stage ( $>10$ tillers), $\sim 10 \%$ of dwarf mutants displayed a prostrate secondary phenotype (data not shown). One of these mutant lines, named Lowboy I (Figure 1b), was further characterized.

Lowboy I plants displayed a consistent growth habit in the field over a 3-year evaluation period, from 2012 to 2014. Lowboy I developed canopy lengths that were only $65-69 \%$ of wild type (Table 2). Similarly, Lowboy I had leaf blade lengths, leaf blade widths and internode lengths reduced to $40-45 \%, 16-18 \%$ and $51-56 \%$ of wild type, respectively. Root lengths were not significantly different between Lowboy I and wild-type, and the ratios of dry root/shoot biomass were slightly higher for Lowboy I.

In field tests of tolerance to low mowing height $(1.9 \mathrm{~cm})$, Lowboy I displayed significantly higher turf density, better leaf texture, and better turf quality than wild type in 2012, 2013 and 2014 (data from 2013 are mentioned in Table 3). Turf density, leaf texture and turf quality were determined according to the procedures described by Morris. ${ }^{26}$ The Lowboy I had a high turf density, whereas wild-type controls had only medium turf density. Lowboy I had close to the best possible turf quality, whereas wild type had quality slightly above the acceptable level. The fact that Lowboy I leaves were narrower than those of wild type improved the appearance of Lowboy I under low mowing height conditions (Table 3). Lowboy I plants also had shorter internodes lengths than wild-type plants, with more leaves retained on the stems at low mowing height.

Wild-type Fiesta 4 perennial ryegrass $\left(0^{\prime \prime}\right)$ was crossed with Lowboy I M2 ryegrass (Q) to produce M3 progeny in order to

Table 1. Effect of gamma-ray dosage on the germination of Fiesta 4 perennial ryegrass seeds

\begin{tabular}{lc}
\hline Dosage $(k r)$ & Germination rate $(\% \pm$ s.e.) \\
\hline 0 & $92.39 \pm 2.02(\mathrm{a})$ \\
2.5 & $78.93 \pm 0.71(\mathrm{~b})$ \\
5.0 & $70.03 \pm 1.52(\mathrm{c})$ \\
7.5 & $55.47 \pm 1.61(\mathrm{~d})$ \\
10.0 & $38.17 \pm 1.03(\mathrm{e})$ \\
15.0 & $24.37 \pm 1.45(\mathrm{f})$ \\
20.0 & $19.10 \pm 0.15(\mathrm{~g})$ \\
\hline
\end{tabular}

Gamma radiation of perennial ryegrass seeds led to differing germination rates. Each value represents the mean germination rates of three replicates. Values in the same column followed by the same letter are not significantly different from each other according to Fisher's least significant difference $(P=0.05)$ determine whether the phenotype observed in Lowboy I M2 plants was stably inherited. We characterized the M3 progeny under greenhouse conditions and observed that $~ 50 \%$ of the M3 plants from the crosses between the wild type $\left(\sigma^{\gamma}\right)$ and Lowboy I (O) were similar to the wild-type controls; these were categorized as tall progeny. The other $50 \%$ were shorter than wild-type plants and were categorized as short progeny. Although the leaf blade lengths of the short group were significantly shorter than those of wild type, they were still significantly longer than those of Lowboy I M2. The tiller numbers of tall and short progeny were not significantly different from those of Lowboy I M2 and wild-type plants (Figure 1c and Table 4). The root lengths of tall progeny were not significantly different from those of Lowboy I M2 and wild-type plants, however, short progeny had significantly shorter root lengths than Lowboy I M2 plants. The dry root/shoot biomasses of short progeny were similar to those of Lowboy I M2 plants and were significantly greater than those of wild type. We also crossed Lowboy I (\$) with Gamma-2 (o"), another dwarf mutant, and were able to get progeny displaying a more compact dwarf phenotype than found in either parental line (Table 4).

In order to verify that the phenotype of Lowboy I was a result of GA deficiency, Lowboy I M2 plants were treated with $\mathrm{GA}_{3}$, and their subsequent growth and morphology was compared with those of wild-type controls. It was found that, over a 3-week period, $\mathrm{GA}_{3}$-treated Lowboy I plants were restored to the same height as wild-type plants. In addition, the prostrate phenotype observed in Lowboy I was completely abolished following $\mathrm{GA}_{3}$ treatment (Figures $2 \mathrm{a}$ and b). These results demonstrate that $\mathrm{GA}_{3}$ treatment is sufficient to restore Lowboy I to a wild-type phenotype, indicating that the mutation found in Lowboy I results in GA deficiency.

\section{DISCUSSION}

Prostrate turf has advantages over upright turf in a number of applications, most notably for low mowing tolerance and improved heat resistance. Prostrate turf can also be more traffic resistant, as leaf blades and stems are more likely to be pressed flat than damaged when in high traffic environments. Prostrate turf can also have better ground coverage, as leaves that lie flat upon the ground obscure areas where turf density is lacking. Prostrate phenotypes can be difficult to screen for in mutation breeding programs due to their delayed presentation. However, as shown in this study, $\sim 10 \%$ of dwarf mutants display a prostrate phenotype at mature stages ( $>10$ tillers). Therefore, it is possible to initially screen for dwarfism, which can be seen at the three-leaf stage, in order to isolate prostrate mutants.

Mowing accounts for $60 \%$ of the overall cost of lawn maintenance. ${ }^{3,30}$ Various methods have been used to reduce mowing costs, including less frequent mowing. However, there are often functional or aesthetic reasons as to why less frequent mowing is undesirable. The most effective way to reduce costs while maintaining a presentable appearance is to use a dwarf turf variety. The Lowboy I perennial ryegrass mutant, reported here, has the potential to reduce mowing frequency significantly. Based on the growth rate of Lowboy I, we expect that its mowing frequency may be reduced by half or two thirds compared with wild type. Our mowing experiments demonstrated that Lowboy I displayed significantly improved tolerance to low mowing height when compared with wild type, with improved turf density, leaf texture and turf quality in a 3-year field study. Lowboy I plants had shorter internodes than wild-type controls, with more leaves retained on the stems after mowing to $1.9 \mathrm{~cm}$. The narrower leaves of Lowboy I also resulted in a better visual appearance after low mowing. Although perennial ryegrass is relatively resistant to low mowing and has been used on golf course fairways, improvement in turf quality at mowing heights under $1.9 \mathrm{~cm}$ would make a perennial ryegrass mutant such as Lowboy I a stellar 

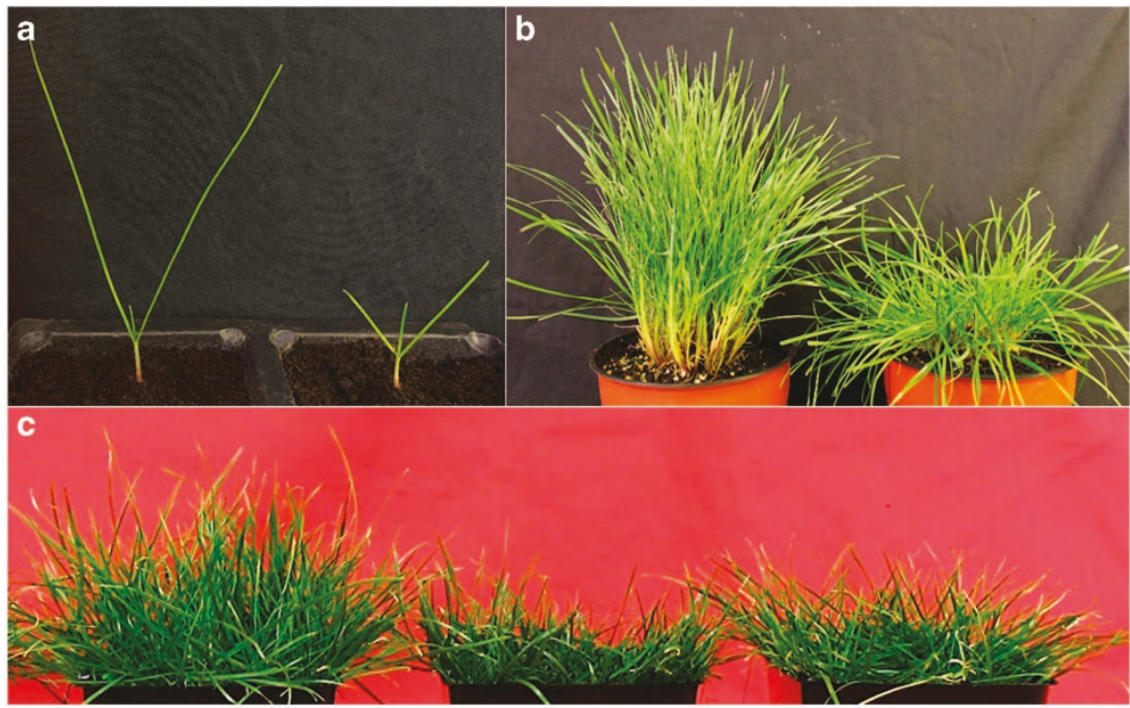

Figure 1. Comparisons of Lowboy I M2, Lowboy I M3 and wild-type (WT) Fiesta 4 perennial ryegrass under various experimental conditions. (a) An 8-week-old Lowboy I M2 mutant (right) exhibited dwarf characteristics compared with WT (left). (b) Lowboy I plants (right) had dwarf and prostrate phenotypes compared with WT (left). (c) Lowboy I M3 plants retained short growth and prostrate characteristics (from left to right: WT, Lowboy I M2 and Lowboy I M3).

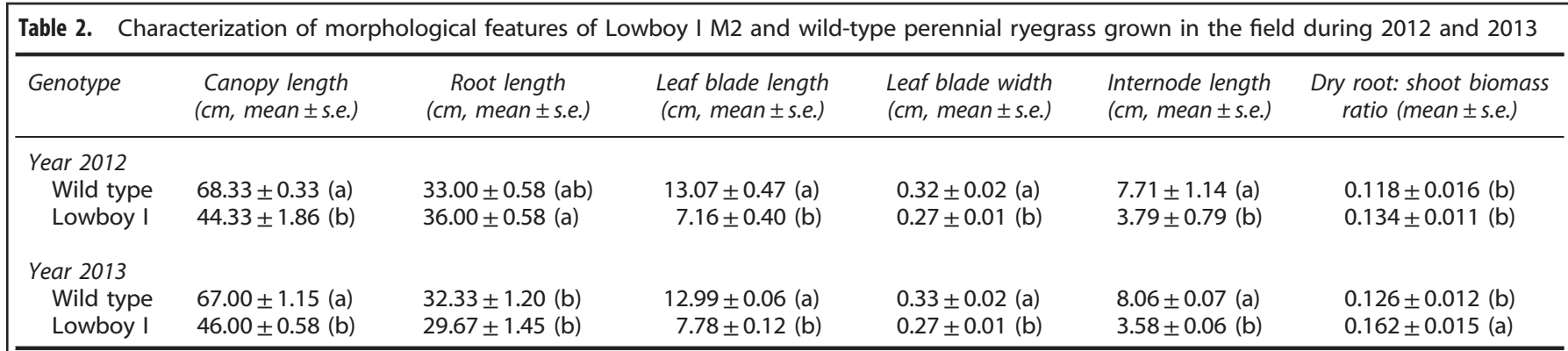

Data were collected in June 2012 and June 2013 (at plant maturity). Each value represents the mean of six replicates, comprised of one plant each. Values in the same column followed by the same letter are not significantly different from each other according to Fisher's least significant difference $(P=0.05)$.

Table 3. Comparison of turf quality characteristics of Lowboy I M2 and wild-type perennial ryegrass after low mowing tolerance testing in 2013

\begin{tabular}{llll}
\hline Genotype & $\begin{array}{l}\text { Turf density } \\
\text { (mean } \pm \text { s.e.) }\end{array}$ & $\begin{array}{l}\text { Leaf texture } \\
\text { (mean } \pm \text { s.e.) }\end{array}$ & $\begin{array}{l}\text { Turf quality } \\
\text { (mean } \pm \text { s.e.) }\end{array}$ \\
\hline Wild type & $5.40 \pm 0.31$ & $5.01 \pm 0.14$ & $6.17 \pm 0.17$ \\
Lowboy I & $7.20 \pm 0.41^{*}$ & $6.90 \pm 0.16^{*}$ & $8.00 \pm 0.58^{*}$ \\
\hline
\end{tabular}

Each value represents the mean of three replicates. Turf density is a measure of the number of aerial shoots per unit area. Turf density rating: $1=$ less dense; $9=$ more dense. Leaf texture is a measure of the width of leaf blades. Fine textured turf grasses have narrow leaves. Leaf texture rating: $1=$ course texture; $9=$ fine texture. Turf quality is a composite score determined by the collective contribution of shoot density and leaf texture, smoothness and color. Turf quality rating: $1=$ poorest possible turf quality; $9=$ best possible turf quality, $5=$ minimum acceptable value for turf quality. Asterisks represent a significant difference from the wild-type samples according to Student's $t$-test $(P \leqslant 0.05)$.

choice for athletic fields as well as golf teeing grounds and fairways.

Perennial ryegrass prefers relatively high amounts of water and fertilizer compared with other turf varieties. ${ }^{1,31}$ Lowboy I displayed dwarfism while maintaining a strong root system under both greenhouse and field conditions. The characteristics of this phenotype that are consistent with those of other dwarf turf varieties have been shown to require less irrigation and fertilization. ${ }^{17-19,32}$ However, additional experiments are needed to determine whether Lowboy I can tolerate reduced water and fertilizer.

The preferred method for growing perennial ryegrass is through seed dispersal. Trait inheritance through sexual reproduction is a basic requirement for commercially relevant cultivars. ${ }^{3,33}$ We have demonstrated that the dwarf phenotype observed in Lowboy I is a dominant trait and can be stably inherited by progeny through sexual reproduction. Furthermore, Lowboy I and Gamma-2 hybridize to produce seeds with a severe dwarf phenotype. It is important to note that Lowboy I plants produced an equivalent seed yield to wild type. These results suggest that Lowboy I can be used as a parental line to cross with other dwarf lines in order to produce progeny with enhanced dwarf phenotypes.

The strategy detailed in this paper for identifying a dwarf, prostrate phenotype in the $\mathrm{M} 2$ generation of perennial ryegrass is dependent upon a dominant mutation as the source of the phenotype. Phenotypes resulting from recessive mutations are invisible to screening because perennial ryegrass is selfincompatible. For a recessive mutation to become visible, it must exist in a homozygous state. Without the ability to self-cross, 


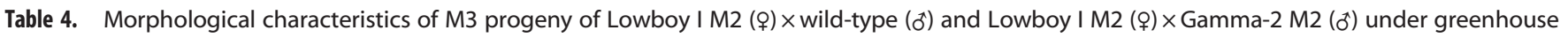
conditions

\begin{tabular}{|c|c|c|c|c|}
\hline Genotype & $\begin{array}{l}\text { Leaf blade length } \\
(\mathrm{cm}, \text { mean } \pm \text { s.e. })\end{array}$ & $\begin{array}{c}\text { Root length } \\
(\mathrm{cm}, \text { mean } \pm \text { s.e. })\end{array}$ & $\begin{array}{l}\text { Tiller number } \\
\text { (mean } \pm \text { s.e.) }\end{array}$ & $\begin{array}{l}\text { Ratio of root/shoot dry } \\
\text { mass (mean } \pm \text { s.e.) }\end{array}$ \\
\hline Wild type & $13.46 \pm 0.40$ (a) & $14.50 \pm 0.29(a b)$ & $12.33 \pm 0.33(\mathrm{a})$ & $0.283 \pm 0.003(b)$ \\
\hline Lowboy I M2 & $6.53 \pm 0.12(d)$ & $14.72 \pm 0.15(\mathrm{a})$ & $12.67 \pm 0.33$ (a) & $0.396 \pm 0.006$ (a) \\
\hline Lowboy I M $2 \times$ wild type (short group) & $8.04 \pm 0.02(b)$ & $13.67 \pm 0.27(b)$ & $12.00 \pm 0.00(\mathrm{a})$ & $0.403 \pm 0.003$ (a) \\
\hline Gamma-2 M2 & $7.02+0.02$ (c) & $14.17+0.38(a b)$ & $13.00 \pm 0.58(a)$ & $0.400+0.002(a)$ \\
\hline Lowboy I × Gamma-2 & $5.96 \pm 0.05(\mathrm{e})$ & $13.67 \pm 0.33(\mathrm{~b})$ & $12.67 \pm 0.33(a)$ & $0.356 \pm 0.015(\mathrm{a})$ \\
\hline
\end{tabular}

Each value represents the mean of six replicates grown under greenhouse conditions, each replicate was one representative plant. Data were collected after 4 months of growth. Values in the same column followed by the same letter are not significantly different from each other according to Fisher's least significant difference $(P=0.05)$.
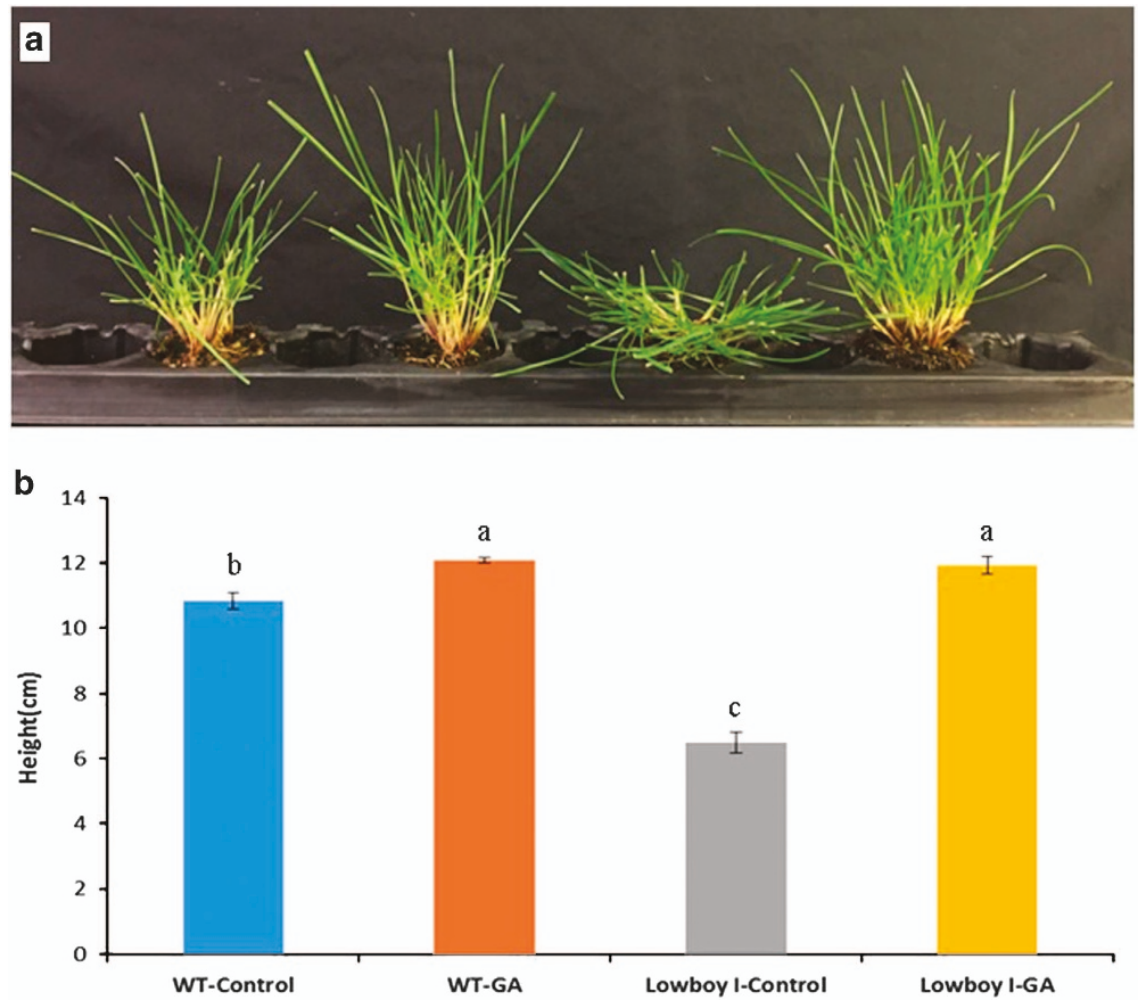

Figure 2. $\mathrm{GA}_{3}$ treatment of Lowboy I M2 and wild-type (WT) Fiesta 4 perennial ryegrass. (a) $\mathrm{GA}_{3}$ treatment was able to restore Lowboy I mutant plants to a WT phenotype (from left to right: untreated WT, WT treated with $\mathrm{GA}_{3}$, untreated Lowboy I and Lowboy I treated with GA ). (b) Lowboy I mutants treated with $\mathrm{GA}_{3}$ became as tall as WT treated with $\mathrm{GA}_{3}$. Each bar represents the mean of six replicates grown under greenhouse conditions, each replicate was one representative plant. Data were collected after 3 weeks of weekly $\mathrm{GA}_{3}$ treatment. Bars with the same letter above them are not significantly different from each other according to Fisher's least significant difference $(P=0.05)$.

mutant alleles cannot become homozygous in perennial ryegrass.

Through the GA treatment of mutant plants, we were able to confirm that Lowboy I mutants were GA deficient, as they were restored to a wild-type phenotype following the application of $\mathrm{GA}_{3}$ to the leaves. GA deficiency was found to be responsible for both the dwarf and prostrate phenotypes observed in the Lowboy I mutant. This is the first reported case of a prostrate phenotype being linked to GA deficiency in perennial ryegrass.

Previous studies in Arabidopsis, maize, rice and other plant species have shown that loss-of-function mutations in GA biosynthetic genes reduce stem and leaf length growth. ${ }^{34-36}$ It has been reported that in barley (Hordeum vulgare), the loss of function of GA3ox1 gene, the enzyme responsible for the last step of GA biosynthesis, led to both dwarfism and prostrate growth. ${ }^{37}$ Ordonio et al. ${ }^{38}$ reported that in their M2 sorghum mutant population, they isolated several prostrate dwarf mutants. Their characterization showed that GA deficiency was the root cause behind both phenotypes. The GA deficiency of these mutants was due to a loss-of-function mutation in one of four genes (SbCPS1, SbKS1, SbKO1 and SbKAO1) that are involved in the early steps of $\mathrm{GA}$ biosynthesis. They used GA treatments to restore the mutant plants to a wild-type phenotype. All of these mutant studies, in addition to the analysis of Lowboy I reported here, demonstrate that prostrate growth is one of the pleiotropic effects of GA deficiency in some monocot plant species. 
However, the mutations in barley, wheat, and sorghum were all recessive, whereas the mutation in Lowboy I is likely dominant. Unlike the sorghum prostrate mutants, it is more likely that the mutant gene found in Lowboy I is a negative regulator of the GA biosynthetic pathway. Cloning and characterization of the mutant gene should provide insight into the molecular basis for dwarfism and prostrate growth in Lowboy I.

\section{CONCLUSIONS}

Gamma-ray irradiation has been used to create dominant mutations for dwarfism in Fiesta 4 perennial ryegrass. One mutant, Lowboy l, displayed both dwarfism and prostration, with improved turf density, turf quality and resistance to low mowing height. The prostrate and dwarf phenotypes of Lowboy I were completely eliminated with exogenous $\mathrm{GA}_{3}$ application, demonstrating that both traits are most likely the result of GA deficiency. The observed Lowboy I phenotypes are also stably inherited in progeny through sexual reproduction. In this study, we demonstrate that mutation breeding can be used to create dominant or semi-dominant mutants in turfgrasses. Furthermore, we show that screening for prostrate mutants of turfgrass can be simplified with an initial screen for dwarfism.

\section{CONFLICT OF INTEREST}

The authors declare no conflict of interest.

\section{ACKNOWLEDGEMENTS}

We thank the personnel at the University of Massachusetts for their kind assistance in gamma-ray irradiation of seed materials. We also thank Mr Steve Olsen and his crew at the University of Connecticut, Plant Science Research and Education Facility for their help in growing and maintaining mutant plant populations. This project is financially supported by the Storrs Agricultural Experiment Station to Y.L. J.C was a PhD intern from Northwest A\&F University and was co-supervised by Y.L. and X.Z.

\section{AUTHOR CONTRIBUTIONS}

J.C. and C.T. did most of the work for mutant isolation and characterization. W.L., Ha.Y., Hu.Y., R.E.-T., L.K.-G., M.M. and Y.C. were involved in greenhouse and field evaluation of the mutant. J.I., R.J.M., K.G. and X.Z. provided advices on characterization of the mutant and manuscript editing. $Y L$ designed experiments for the mutant isolation and characterization. J.C., C.T., W.L., L.K.-G., and Y.L. were involved in manuscript writing and editing.

\section{REFERENCES}

1 Meyer WA, Funk CR. Contributions from Breeding Forage and Turf Grasses. CSSA Special Publication: Madison, WI, USA, 1989.

2 Pearson A, Cogan NOI, Baillie RC, Hand ML, Bandaranayake CK, Erb S et al. Identification of QTLs for morphological traits influencing water logging tolerance in perennial ryegrass (Lolium perenne L.). Theor Appl Genet 2011; 122: 609-622.

3 Brede D. Turfgrass Maintenance Reduction Handbook: Sports, Lawns, and Golf. John Wiley \& Sons Inc. Press: New York, USA, 2000.

4 Puhalla J, Krans J, Goatley M. Baseball and Softball Fields: Design, Construction, Renovation, and Maintenance. John Wiley \& Sons Inc. Press: New York, USA, 2003.

5 Ebdon JS, Petrovic AM. Morpholog-Ical and growth characteristics of low- and high-water use kentucky bluegrass cultivars. Crop Sci 1998; 38: 143-152.

6 Leinauer B, Sevostianova E, Serena M, Schiavon M, Macolino S. Conservation of irrigation water for urban lawn areas. Acta Hortic 2010; 881: 487-492.

7 Leinauer B, Serena M, Schiavon M, Sevostianova E. Water demands and water conservation strategies in turfgrass management. Acta Hortic 2012; 938: 113-120.

8 Inguagiato J, Murphy J, Clarke B. Anthracnose disease and annual bluegrass putting green performance affected by mowing practices and lightweight rolling. Crop Sci 2009; 49: 1454-1462.

9 Youngner VB. Turfgrass Science. American Society of Agronomy Monograph 14: Madison, WI, USA, 1969, pp 187-216.

10 Beard JB. Turfgrass: Science and Culture. Prentice Hall: Englewood Cliffs, NJ, USA, 1973.

11 FAO/IAEA database, 2014. Available at: http://www-infocris.iaea.org/MVD/.
12 Ahloowalia BS, Maluszynski M, Nichterlein K. Global impact of mutation-derived varieties. Euphytica 2004; 135: 187-204.

13 Maluszynski M, Nichterlein K, van Zanten L, Ahloowalia BS. Officially released mutant varieties - the FAO/IAEA Database. Mut Breed Rev 2000; 12: 1-84.

14 Dickens R, Johnston WJ, Haaland RL. Variability observed in centipedegrass grown from ${ }^{60}$ Co irradiated seed. Agron J 1981; 73: 674-676.

15 Busey P. Gamma ray dosage and mutation breeding in St Augustinegrass. Crop Sci 1980; 20: 181-184.

16 Krishna G, Shivashankar G, Nath J. Mutagenic response of rhodes grass (Chloris gayanaKunth) to gamma rays. II. Studies on second (M2) generation parameters. Euphytica 1984; 33: 517-524.

17 Burton GW. Registration of Tifway II bermudagrass. Crop Sci 1985; 25: 364-364.

18 Hanna WW, Carrow RN, Powell AJ. Registration of 'Tift 94' bermudagrass. Crop Sci 1997; 37: 1012-1012.

19 Hanna WW, Elsner JE. Registration of 'TiftEagle' bermudagrass. Crop Sci 1999; 39: 1258-1258.

20 Lu S, Wang Z, Niu Y, Guo Z, Huang B. Antioxidant responses of radiation-induced dwarf mutants of bermudagrass to drought stress. J Am Soc Hortic Sci 2008; 133: 360-366.

21 Lu S, Wang Z, Niu Y, Chen Y, Chen H, Fan Z et al. Gamma-ray radiation induced dwarf mutants of turf-type bermudagrass. Plant Breeding 2009; 128: 205-209.

22 Chen C, Lu S, Chen Y, Wang Z, Niu Y, Guo Z. A gamma-ray-induced dwarf mutant from seeded bermudagrass and its physiological responses to drought stress. J Am Soc Hortic Sci 2009; 134: 22-30.

23 Wilkins PW, Thorogood D. Breakdown of self-incompatibility in perennial ryegrass at high temperature and its uses in breeding. Euphytica 1992; 64: 65-69.

24 Peng J, Richards D, Hartley N, Murphy G, Devos K, Flintham JE et al. 'Green revolution' genes encode mutant gibberellin response modulators. Nature 1999; 400: 256-261.

25 Spielmeyer W, Ellis M, Chandler P. Semidwarf (sd-1), 'green revolution' rice, contains a defective gibberellin 20-oxidase gene. Proc Natl Acad Sci USA 2002; 99: 9043-9048.

26 Morris KN. A Publication of the National Turfgrass Evaluation Program, Vol 11. The National Turfgrass Evaluation: Beltsville, MD, USA, 2002, pp 30-39.

27 Steel RGD, Torrie JH, Dickey DA. Principles and Procedures of Statistics: A Biometrical Approach. McGraw Hill Co., Inc: New York, USA, 1997.

28 Li R, Bruneau AH, Qu R. Morphological mutants of St Augustinegrass induced by gamma ray irradiation. Plant Breeding 2010; 129: 412-416.

29 van Harten AM. Mutation breeding: theory and practical applications. Cambridge University Press: Cambridge, 1998.

30 Bormann HF, Balmori D, Geballe GT. Redesigning the American Lawn: a Search for Environmental Harmony. Yale University Press: New Haven, CT, USA, 2001.

31 Langille AR, Pennucci A. An evaluation of turfgrass species and varieties: perennial ryegrass. Maine Agricultural and Forest Experiment Station Miscellaneous Report 416. University of Maine: Orono, ME, USA, 2000.

32 Goss RL, Law AG. Performance of bluegrass varieties at two cutting heights and two nitrogen levels. Agron J 1967; 59: 516-518.

33 Casler MD, Duncan RR. Turfgrass Biology, Genetics, and Breeding. John Wiley \&Sons Inc. Press: New York, USA, 2003.

34 Fujioka S, Yamane H, Spray CR, Gaskin P, Macmillan J, Phinney BO et al. Qualitative and quantitative analyses of gibberellins in vegetative shoots of normal, dwarf-1, dwarf-2, dwarf-3, and dwarf-5 seedlings of Zea mays L. Plant Physiol 1988; 88: 1367-1372.

35 Helliwell CA, Sheldon CC, Olive MR, Walker AR, Zeevaart JA, Peacock WJ et al. Cloning of the Arabidopsis ent-kaurene oxidase gene GA3. Proc Natl Acad Sci USA 1998; 95: 9019-9024.

36 Sakamoto T, Miura K, Itoh H, Tatsumi T, Ueguchi-Tanaka M, Ishiyama K et al. An overview of gibberellin metabolism enzyme genes and their related mutants in rice. Plant Physiol 2004; 134: 1642-1653.

37 Wolbang CM, Davies NW, Taylor SA, Ross JJ. Gravistimulation leads to asymmetry of both auxin and gibberellin levels in barley pulvini. Physiol Plant 2007; 131: 140-148.

38 Ordonio RL, Ito Y, Hatakeyama A, Ohmae-Shinohara K, Kasuga S, Tokunaga T et al. Gibberellin deficiency pleiotropically induces culm bending in sorghum: an insight into sorghum semi-dwarf breeding. Sci Rep 2014; 4: 5287.

This work is licensed under a Creative Commons Attribution 4.0 International License. The images or other third party material in this article are included in the article's Creative Commons license, unless indicated otherwise in the credit line; if the material is not included under the Creative Commons license, users will need to obtain permission from the license holder to reproduce the material. To view a copy of this license, visit http://creativecommons.org/licenses/ by/4.0/ 